\title{
O povo que falta, nós já tínhamos: sobre escrita e perspectivismo
}

\author{
Adriana Bolite Frant ${ }^{1}$
}

Já tínhamos o comunismo. Já tínhamos a língua surrealista. A idade de ouro.

Catiti Catiti

Imara Notiá

Notiá Imara

Iрејu

A magia e a vida. Tínhamos a relação e a distribuição dos bens físicos, dos bens morais, dos bens dignários. E sabiamos transpor o mistério e a morte com o auxilio de algumas formas gramaticais.

Oswald de Andrade

Não existe obra de arte que não faça apelo a um povo que ainda não existe

Gilles Deleuze

\section{Perspectivismo e antropofagia}

No capítulo de Tristes trópicos (1955) intitulado "Lição de escrita", Lévi-Strauss relata que, ao se juntar aos índios nambiquara, constata que estes não possuem escrita e desconhecem o desenho, a não ser por breves inscrições geométricas que fazem em suas cabaças. É a partir dessa constatação que distribui entre eles papel e lápis, com os quais passam a traçar linhas horizontais onduladas. "Está claro que os nambiquara não sabem escrever", conclui o antropólogo (Lévi-Strauss, 1957, p. 314). Dando sequência a seu relato, Lévi-Strauss descreve como, para seu espanto, durante uma cerimônia de troca de dádivas, o chefe nambiquara lhe pede um de seus cadernos de notas, e, aparentemente, tendo compreendido a função da escrita, passa a traçar nele linhas sinuosas em vez de lhe comunicar verbalmente os trâmites da

${ }^{1}$ Doutoranda do Programa de Pós-Graduação em Literatura, Cultura e Contemporaneidade da Pontifícia Universidade Católica do Rio de Janeiro (PUC-Rio), Rio de Janeiro, RJ, Brasil. E-mail: drnfrnt@gmail.com 
negociação que estava acontecendo. O chefe estaria, por meio desse ato de escrita, designando quais seriam os presentes trocados.

Ele próprio como que se ilude com a sua comédia; cada vez em que a sua mão termina uma linha, examina-a ansiosamente, como se a significação devesse brotar, e a mesma desilusão se pinta no seu rosto. Mas não a admite; está tacitamente entendido entre nós que os seus riscos possuem um sentido que eu finjo decifrar; o comentário verbal segue-se quase imediatamente, e me dispensa de pedir os esclarecimentos necessários (Lévi-Strauss, 1957, p. 315).

O chefe nambiquara então, por pertencer a um coletivo que, na percepção do etnólogo, não possui escrita e mal possui o desenho, o surpreende ao ensaiar essa escrita performativa e mimética durante a cerimônia de trocas. Sobre essa cena, amplamente debatida por Jacques Derrida em Gramatologia (1967), detém-se também Marília LibrandiRocha, em Escutar a escrita: por uma teoria literária ameríndia (2012). Ao retomar esse feito do chefe nambiquara, Librandi-Rocha busca pensar de que forma essas linhas sinuosas constituem uma performance, um ato artístico. Derrida, ao deslocar e ampliar o que Lévi-Strauss designa como escrita, propondo a noção alargada de escritura, coloca em questão o etnocentrismo do antropólogo quando este se refere aos nambiquara como um povo não letrado. Em um movimento similar, Librandi-Rocha desloca as noções de arte e performance para pensar o gesto do chefe nambiquara como um gesto performático, aproximando-se assim da noção de xamanismo, conforme proposta por Eduardo Viveiros de Castro em Perspectivismo e multinaturalismo na América indígena (2002). Ao propor esse deslocamento, Librandi-Rocha chama atenção para a questão do ponto de vista, argumentado que tanto Derrida quanto Lévi-Strauss não atentam para o silêncio das linhas sinuosas do chefe. Em sua concepção, portanto, permanece em aberto ainda hoje a questão do ponto de vista, ou seja, "o que ainda está para ser dito e pensado é, pois, o ponto de vista indígena sobre essas linhas" (Librandi-Rocha, 2012, p. 181).

Nesse âmbito, a noção de xamanismo seria uma chave para se pensar o gesto artístico fora da clausura em que este se encontra nos circuitos das sociedades ditas modernas e ocidentais. $\mathrm{Na}$ esteira desses questionamentos, ecoa também o manifesto antropófago de Oswald de Andrade. Ao declarar "só me interessa o que não é meu", Oswald se aproxima do xamanismo amazônico, conforme descrito por Viveiros de Castro. Se o perspectivismo ameríndio pode ser definido "como a 
concepção, comum a muitos povos do continente, segundo a qual o mundo é habitado por diferentes espécies de sujeitos ou pessoas, humanas e não humanas, que o apreendem segundo pontos de vista distintos" (Castro, 2002), o xamanismo seria justamente

a habilidade manifesta por certos indivíduos de cruzar deliberadamente as barreiras corporais e adotar a perspectiva de subjetividades alo-específicas, de modo a administrar as relações entre estas e os humanos. Vendo os seres não humanos como estes se veem (como humanos), os xamãs são capazes de assumir o papel de interlocutores ativos no diálogo transespecífico; sobretudo, eles são capazes de voltar para contar a história, algo que os leigos dificilmente podem fazer (Castro, 2002, p. 231).

Esse cruzar de fronteiras consiste em tomar o ponto de vista do outro, habitar outras subjetividades, inclusive conceber a possibilidade de uma subjetividade extra-humana. Enfim, todas essas tomadas de posições através das quais se define o xamanismo aproximam-se desse "só me interessa o que não é meu", proposto por Oswald. É nesse âmbito que Viveiros de Castro sugere compreender o perspectivismo ameríndio como a retomada da antropofagia oswaldiana em novos termos. Esse parentesco entre o perspectivismo e a antropofagia se dá não apenas em termos conceituais, mas também no que tange a uma possibilidade de ação ética e política capaz de combater a sujeição cultural que abala tantos os índios como os não índios da América Latina (Castro, 2012, p. 129). Nesse âmbito, o ato artístico constitui-se também num ato político e de resistência.

Antônio Risério, em Textos e tribos (1993), ensaia uma leitura da tese de doutorado de Viveiros sobre os índios Araweté (Castro, 1986), ressaltando o caráter artístico, poético e antropofágico do xamanismo. Nesse coletivo, o xamã não fala por si, mas funciona como um veículo de transmissão da palavra divina. Durante sua performance, uma pluralidade de vozes se faz presente através de seu canto. O xamã atua, então, como um poeta-músico ao entoar seus cânticos (Risério, 1993, p. 163). Como o próprio Risério afirma, que os xamãs são poetas, ninguém hoje se atreve a negar. O que este trabalho pretende é pensar os desdobramentos e deslocamentos dos conceitos ocidentalistas de "literatura", "escrita", "poesia" e, em suma, "arte" a partir dessas questões. O perspectivismo ameríndio pode ser compreendido como uma proposta conceitual produtiva para pensar uma antropologia da 
arte e uma teoria literária simétrica, pois através dessa abordagem é possível produzir uma torção desses conceitos em uma tentativa de descolonização do pensamento. Trata-se, portanto, de buscar pensar e produzir uma teoria literária ameríndia, para qual Librandi-Rocha chama atenção já no título de seu texto.

\section{Dificuldades conceituais e teóricas}

Alfred Gell, em Art and agency: an antrhopological theory (1998), sugere fazer uma antropologia da arte fora dos moldes nos quais ela vinha sendo feita até então, segundo ele. Em sua proposta, Gell deixa claro que, sendo a antropologia uma disciplina das ciências sociais e não das humanidades, sua forma de abordar a arte não se dá mediante a avaliação estética de artefatos, mas, sim, na busca por compreender como determinados objetos circulam, ou seja, quais as relações que eles estabelecem através de um processo que chama de abdução de agência. Sua tese principal vê a arte não como um sistema de representação do mundo, mas de construção de mundo. Nessa concepção, o desejo de ver a arte de outras culturas a partir do paradigma estético, nos diria mais sobre nossa própria ideologia e a sua veneração quase-religiosa dos objetos de arte, que sobre essas outras culturas (Gell, 1998, p. 12). Nesse âmbito, o objeto de estudo da antropologia não seria a cultura, mas as relações sociais, pois, nessa concepção, a cultura não existe independentemente de suas manifestações em interações sociais.

Levando adiante essas questões, Gell inicia um debate com o filósofo da arte Arthur Danto. Em 1988, em Nova Iorque, ocorre no centro de arte africana uma exposição com curadoria de Susan Vogel, em que estava exposta uma rede de caça Azande. No catálogo da exposição, Danto argumenta que a rede não deveria ser tomada com um objeto de arte, pois foi concebida originalmente como um objeto técnico e utilitário. Conforme relata Giumbelli sobre esse debate, Gell, ao contrário, propõe que se considere a rede Azande como uma obra de arte, lembrando que, em muitas culturas não ocidentais, as atividades de caça são elas mesmas partes de rituais, e seus objetos são aí ritualmente concebidos - o que solapa a distinção que Danto pretende ver entre o expressivo e o instrumental, entre a arte e o artefato (Giumbelli, 2006). ${ }^{2}$ Esse episódio, exposto aqui brevemente, ilustra as

\footnotetext{
${ }^{2}$ Para uma leitura mais aprofundada desse debate ver Gell (2009).
} 
dificuldades conceituais e teóricas ao se propor uma teoria literária ameríndia. Apesar do debate entre Gell e Danto tratar de objetos de arte, ele pode ser expandido para se pensar também a questão da escrita.

$\mathrm{Na}$ esteira dessas questões, Viveiros de Castro, alinhado à antropologia da arte proposta por Gell, define o perspectivismo ameríndio não como um relativismo, mas um relacionalismo, chamando atenção para a importância do estatuto das relações no mundo ameríndio. Entender, portanto, como se dão essas relações é o ponto de partida para a compreensão da antropologia da arte tal como elucidada por Gell. Sob sua perspectiva, a ênfase para se pensar a arte está na agência, na intenção, no resultado e na transformação. A arte funciona como um sistema de ação que pretende transformar o mundo em vez de representá-lo por meio de códigos simbólicos. Sua proposta busca compreender as situações que envolvem o fazer artístico como um índice de uma determinada operação cognitiva, operação que denomina de abdução de agência (Gell, 1998). O termo abdução, emprestado da semiótica, refere-se às inferências feitas quando em contato com um "índice", expressão que indica um evento visual provocador da inferência em questão. A fumaça é o exemplo mais clássico de um índice, sendo a inferência "onde há fumaça, há fogo" uma possível abdução. Nesse sentido, a abdução não é uma dedução lógica, pois certamente outras causas podem explicar a aparição da fumaça. Agência, ainda segundo Gell, é tudo que é dotado de intenção, ou causado por um agente social, que pode ser uma coisa, um objeto (de arte) ou uma pessoa, humana ou extra humana. O perspectivismo ameríndio ajuda-nos a pensar como uma coisa ou uma pessoa extra-humana também pode ser dotada de agência. Para exemplificar a noção de agência social, Gell dá o exemplo da relação de uma menina com sua boneca: se, em um acidente em alto mar, a menina tivesse que escolher entre salvar a boneca ou o irmão mais velho que vive a importuná-la, ela certamente escolheria salvar a boneca. E o tipo de afeição que a criança tem pela boneca não está tão distante da afeição que nós adultos temos por estátuas, como o David de Michelangelo por exemplo, porém mais do que a capacidade desses objetos representarem agências humanas, Gell está interessado na forma em que a agência social emana de diferentes formas desses objetos. Que "ações congeladas" eles contêm. Conforme atenta Viveiros de Castro, "os artefatos possuem esta ontologia interessantemente ambígua: são objetos, mas apontam necessariamente para um sujeito, pois são como ações 
congeladas, encarnações materiais de uma intencionalidade não material" (Castro, 2002, p. 233). Um ponto importante ressaltado por Gell, é que os agentes sociais só agem, justamente, em um contexto social. A boneca emana uma abdução de agência no contexto específico em que se relaciona com a menina, assim como o David de Michelangelo, e o carro de um americano médio que o usa todos os dias para ir trabalhar. A "coisa em si" não é o foco do interesse de Gell, mas o contexto em que essas relações entre coisas se dão. Esse ponto é também um ponto crucial para o perspectivismo ameríndio, pois para esses povos, a relação com o mundo é uma relação social. Viveiros de Castro exemplifica esse fato ao descrever como todos os termos na linguagem ameríndia são termos relatores, ou predicados de dois lugares:

Ora, o que parece ocorrer no perspectivismo indígena é que substâncias nomeadas por substantivos como "peixe", "cobra", "rede" ou "canoa" são usados como se fossem relatores, algo entre o nome e o pronome, o substantivo e o dêitico. (Há, supostamente, uma diferença entre nomes de natural kinds como "peixe" e nomes de artefatos como "rede".) Alguém é um pai apenas porque existe outrem de quem ele é o pai: a paternidade é uma relação, ao passo que a "peixidade" ou a "serpentitude" é uma propriedade intrínseca dos peixes e cobras. O que sucede no perspectivismo, entretanto, é que algo também só é peixe porque existe alguém de quem este algo é o "peixe" (Castro 2002, p. 233).

Viveiros de Castro desenvolve de forma aprofundada essa questão do caráter relacional das sociedades ameríndias a partir do estatuto dos "espíritos" xapiripë, em Floresta de cristal: notas sobre a ontologia dos espíritos amazônicos (2006). Nesse artigo, Viveiros propõe uma reflexão sobre a ontologia dos espíritos na Amazônia indígena a partir de uma narrativa de Davi Kopenawa, pensador e líder político Ianomâmi, sobre os xapiripë, ancestrais animais ou espíritos xamânicos que interagem com os xamãs de seu povo. Segundo David Kopenawa,

os espíritos xapiripë dançam para os xamãs desde o primeiro tempo e assim continuam até hoje. Eles parecem seres humanos, mas são tão minúsculos quanto partículas de poeira cintilantes. Para poder vê-los deve-se inalar o pó da árvore yãkõanahi muitas e muitas vezes. Leva tanto tempo quanto para os brancos aprender o desenho de suas palavras (Kopenawa apud Castro, 2006, p.138). 
A partir desse relato, ${ }^{3}$ Viveiros de Castro aponta para o fato de que o que traduzimos como "espíritos" designa outro tipo de evento, distante daquilo que à primeira vista a palavra espírito evoca. "Um espírito na Amazônia indígena, é menos assim uma coisa que uma imagem, menos uma espécie que uma experiência, menos um termo que uma relação, menos um objeto que um evento" (Castro, 2006, p. 326). Ao constatar que esses seres não são tipos ou representações, mas que de fato habitam uma zona de vizinhança entre os humanos e não humanos, Viveiros de Castro indaga porque então as categorias de "animais" e "humanos" não poderiam possuir esse mesmo grau de indiscernibilidade? Como os espíritos, essas categorias seriam dispositivos de imaginação.

Aqui parece propício voltarmos para a questão levantada por Librandi-Rocha ao propor uma teoria literária ameríndia, pois, se humanos, espíritos e animais (e outros seres da floresta) são dispositivos de imaginação, não estariam eles em pé de igualdade com o que denominamos como seres de ficção? Os seres de ficção, assim como outras figuras da alteridade, como os animais e os índios, foram, no "mundo moderno", empurrados para um outro lado do espectro, onde muitas vezes lhes tem sido negada a possibilidade de existir. É com essas questões em mente que Librandi-Rocha chama atenção para a declaração de Guimarães Rosa, quando este diz "Riobaldo é meu irmão". Ao declarar seu parentesco com esse ser de ficção, Rosa reafirma o aspecto relacional entre as pessoas (humanas e não humanas) que o perspectivismo ameríndio deflagra, instaurando essa capacidade de existirmos em outras frequências, com outras vibrações ou modulações intensivas e contínuas.

\section{Os seres de ficção}

Bruno Latour, em An inquiry into modes of existence: an anthropology of the moderns (2013), pretendendo fazer o que ele designa de antropologia simétrica, escolhe como seus nativos os "modernos". Para tanto, ele vai direto no coração das instituições que compõem o sistema central da sociedade moderna: a ciência, o direito e a religião, onde identifica 15 modos de existência. Um desses modos é justamente o dos seres da ficção (beings of fiction), que, conforme sugere, apesar da insistência dos

\footnotetext{
${ }^{3}$ Posteriormente publicado em A queda do céu (2015)
} 
modernos em dizer que não, de fato existem e se colocam entre nós após se instalarem naqueles responsáveis por sua criação. Nesse sentido, esses seres são mais constituintes que criadores ou inventores, pois, ao contrário do que rege o senso comum, eles não aparecem na nossa imaginação, mas de fato, são eles que nos oferecem uma imaginação (Latour, 2013, p. 240). Ao afirmar que somos o fruto de nossas obras, que a imaginação não é a causa, mas o receptáculo dos seres de ficção, Latour parece estar se aproximando da ideia de que a qualidade relacional, conforme destacada por Gell e Viveiros de Castro, é intrínseca para o processo de abdução de agência. O que chama atenção aqui é que Latour está propondo que os seres de ficção são capazes de emanar essa abdução, assim como os artefatos e obras de artes materiais. LibrandiRocha sugere que uma teoria literária ameríndia se aproxima de certa forma dos moldes da antropologia simétrica, pois busca repensar a literatura não indígena com um pensamento indígena. Se o xamã vai lidar com os seres da ficção (e com os objetos de arte) ele irá se comunicar, interagir e relatar essa comunicação. Por isso, o papel e as linhas sinuosas, no caso do chefe nambiquara, falam com ele, tornam-se um com ele. Nesse sentido, essa performance desencadeada pelos traços sinuosos das linhas inaugura, segundo Librandi-Rocha, um fato original de linguagem. Voltemos então à cena de "Lição de escrita" por ela retomada:

Digamos que a arte nasce do gesto do índio; a mimesis artística tem como arquétipo esse gesto inconsequente, o de uma cópia que vai se transformar em mimesis, pois a partir de uma base de semelhança produz uma diferença. Seu gesto também cria instabilidade semântica, que vai gerar o esforço interpretativo de Lévi-Strauss no momento de insônia. O sonho do índio (escrever como os brancos) vai acordar o antropólogo de seu sono e despertar a crítica de sua cultura de origem (Librandi-Rocha, 2012, p. 195).

Apesar de não concordar com a proposta de que o sonho do índio é querer escrever como os brancos - "É uma falsa alternativa que nos faz dizer: ou imitamos ou somos" (Deleuze e Guattari, 1997, p. 19) -, não há dúvidas de que ele inaugura ali um gesto artístico, um ato performágico. ${ }^{4} \mathrm{O}$ chefe nambiquara certamente encontrou a zona de vizinhança da escrita, tornou-se escritor.

\footnotetext{
${ }^{4}$ Expressão usada por Antônio Risério ao se referir a cena do Canto da Castanheira.
} 
Escrever, "formar", no informe um sentido ausente. Um sentido ausente (não uma ausência de sentido, nem um sentido que faltaria, potencial ou latente). Escrever é talvez trazer à superfície algo como um sentido ausente, receber o impulso passivo que não é ainda pensamento, sendo já o desastre do pensamento. Sua paciência (Blanchot, 1980, p. 71). ${ }^{5}$

As linhas sinuosas parecem pertencer a essa escrita, que produz um sentido ausente e algo que não é ainda pensamento, mas já é seu desastre. O desastre do pensamento é a insônia de Lévi-Strauss. E a cena, no pátio da aldeia e causadora de insônia, remete-nos a outra cena, também operada por um xamã, também no pátio de uma aldeia e que também interrompe um sono. Essa outra cena é a do Canto da castanheira, descrita por Viveiros de Castro e retomada por Antônio Risério em Textos e tribos. O evento se passa em uma aldeia dos índios Araweté, um povo que, como vimos, tem uma relação especial com o canto. Suas indumentárias, arquitetura e artefatos não são visualmente chamativas ou belas. "Tudo para os araweté é palavra [...] o imaginário araweté prolifera na palavra e no canto" (Risério, 1993, p. 151). A cosmologia da tribo parece indicar de onde vem a importância do canto e da palavra: foi através do canto, em um momento inicial, que os deuses teriam subido aos céus. Os deuses araweté são deuses poetas, deuses cantores. Levada pelos deuses e cultivada pelos humanos, a palavra-canto existe assim na terra como no céu e é através dela que esses mundos se comunicam.

Para contextualizar a cena em que se deu o Canto, é importante ressaltar que, para os araweté, o xamanismo se dá de modo diferente de outros povos ameríndios, pois não exige do xamã uma iniciação. Não há um chamado, não há um ritual de passagem ou de possessão. Ainda assim, o xamã viaja entre os mundos e se comunicada com os deuses, sendo o intermediário entre estes e os humanos. Nesse âmbito, o xamã, como um rádio, transmite suas vozes e seus cantos, pois o xamã é um poeta-músico, e sua função mais saliente é a de cantador. Dito isso, vamos à cena.

O xamã acorda de um sonho no meio da noite e dirige-se ao pátio da aldeia, onde começa e entoar um canto. Esse acontecimento é um fato diário, porém é importante ressaltar que esse canto é um canto único, uma instância criativa desse momento, assim como a performance do

${ }^{5}$ Tradução libre de Helena Franco Martins. 
chefe nambiquara. Risério relata, para a surpresa de muitos, que o canto da castanheira, antes que relíquia de eras longínquas, é uma criação recente. Foi apresentado na aldeia Ipixuna pelo xamã Kãñipaye-ro, na madrugada do dia 26 de dezembro de 1982.

A cena do canto é complexa, misturável. Estas personagens giram em um espaço ambíguo ou magicamente nuvioso, numa superposição dos mundos célico e terráqueo. Ou como se as coisas se passassem numa zona de fronteiras abertas. É a isto que nos conduz a "indecisão" espacial do texto. A ação ora transcorre na terra, ora no patamar celestial, quando não se dá simultaneamente aqui e lá, dissolvendo demarcações, como no momento em que os deuses estão na superfície terrestre emplumando uma castanheira que está no céu... geografia xamânica (Risério, 1993, p. 170).

As duas cenas desencadeadas pelos atos performativos indígenas, a da escrita sinuosa do chefe nambiquara e a do canto poético do xamã Kãñipaye-ro penetram nessa zona de indiscernibilidade, fazendo aparecer, brevemente, na superfície, esses espíritos, na concepção xapiripë do termo. Dispositivos de imaginação. O xamanismo, sugere Viveiros de Castro, é uma arte, ou melhor dizendo é $a$ arte. Deleuze e Guattari definem o ato de criação como o ato da escrita em seu sentido alargado, como o de escrever/ criar (para) um povo que falta.

a saúde como literatura, como escrita, consiste em inventar um povo que falta. Pertence à função fabuladora inventar um povo [...] precisamente, não é um povo chamado a dominar o mundo. É um povo menor, eternamente menor, absorvido num devir-revolucionário [...] Fim último da literatura, distinguir no delírio essa criação de uma saúde, ou essa invenção de um povo, quer dizer, uma possibilidade de vida. Escrever para esse povo que falta (Deleuze, 1997, p. 14).

A escrita e, portanto, a literatura, nessa concepção, compreendem uma abertura para a alteridade, para a produção e a criação de novas formas de vida. Nesse sentido, compreende também um ato de resistência. A imagem de um povo que falta, recuperada por Deleuze e Guattari, a partir da proposição de Paul Klee, traz à tona o caráter político e de resistência da obra de arte. "Qual a relação entre a luta dos homens e a obra de arte?" - indaga Deleuze (1999, p. 5). A resposta não está dada, pois não é simples nem autoevidente. Essa indagação não se resolve 
através de uma reposta, em vez disso, opera seu efeito justamente mantendo em suspenso as forças que tenciona e articula. "Falta o povo quer dizer que essa afinidade fundamental entre a obra de arte e um povo que ainda não existe nunca será clara. Não existe obra de arte que não faça apelo a um povo que ainda não existe" (Deleuze, 1999, p. 5). É a partir dessa relação, entre o ato de criação e o povo que falta, que ensaiase aqui uma conclusão, porém uma conclusão nos moldes da indagação de Deleuze, pois não busca explicar, e de fato não conclui ou encerra as questões aqui expostas, mas ergue um arco de tensão sob (e sobre) o qual esse trabalho se insere. O povo que falta, nós já tínhamos.

\section{Referências}

ANDRADE, Oswald de (1976). O manifesto antropófago. In: TELES, Gilberto Mendonça. Vanguarda europeia e modernismo brasileiro: apresentação e crítica dos principais manifestos vanguardistas. 3. ed. Petrópolis: Vozes; Brasília: INL.

BLANCHOT, Maurice (1980). L'écriture do desastre. Paris: Gallimard.

CASTRO, Eduardo B. Viveiros de (1986). Araweté: os deuses canibais. Rio de Janeiro: Jorge Zahar.

CASTRO, Eduardo B. Viveiros de (2002). Perspectivismo e multinaturalismo na América indígena. In: CASTRO, Eduardo B. Viveiros de. A inconstância da alma selvagem. São Paulo: Cosac Naify.

CASTRO, Eduardo B. Viveiros de (2006). A floresta de cristal: notas sobre a ontologia dos espíritos amazônicos. Cadernos de campo, São Paulo, n. 14/15, p. 318-338.

DELEUZE, Gilles (1987/1999). O ato de criação. Folha de S. Paulo, São Paulo, 27 jun, p. 4.

DELEUZE, Gilles (1997). Crítica e clínica. Tradução de Peter Pál Pelbart. São Paulo: 34.

DERRIDA, Jacques (1967/1973). Gramatologia. São Paulo: Edusp.

GELL, Alfred (1998). Art \& agency: an antrhopological theory. Nova Iorque: Oxford University Press.

GELL, Alfred (2009). Vogel's net: traps as artworks and artworks as traps. In: MORPHY, Howard; PERKINS, Morgan (Ed.). The anthropology of art: a reader. Hoboken: Wiley-Blackwell. 
GIUMBELLI, Emerson (2006). Os azande e nós: experimento de antropologia simétrica. Horizontes Antropológicos, Porto Alegre, v. 12, n. 26, p. 261297. Disponível em: <https://goo.gl/2kh9RP>. Acesso em: 10 ago. 2017.

LATOUR, Bruno (2013). An inquiry into modes of existence. Cambridge: Harvard University Press.

LÉVI-STRAUSS, Claude (1957). Tristes trópicos São Paulo: Anhembi.

LIBRANDI-ROCHA, Marília (2012). Escutar a escrita: por uma teoria literária ameríndia. O Eixo e a Roda, Belo Horizonte, v. 21, n. 2, p. 179-202.

RISÉRIO, Antônio (1993). Textos e tribos. Rio de Janeiro: Imago.

Recebido em 13 de fevereiro de 2017.

Aprovado em 17 de julho de 2017.

\section{resumo/abstract/resumen}

\section{O povo que falta, nós já tínhamos: sobre escrita e perspectivismo}

Adriana Bolite Frant

A partir do clássico "Lição de escrita", de Lévi-Strauss, e pelas releituras desse texto efetuadas por Derrida e Librandi-Rocha, este artigo busca pensar como o perspectivismo ameríndio se relaciona com a noção alargada de escrita proposta por Derrida e, ainda, com o ato de criação sugerido por Deleuze. A discussão prossegue pensando como a teoria literária ameríndia se relaciona com a máxima oswaldiana de que "só me interesso por aquilo que não é meu", ou seja, compreende a literatura e a escrita como uma abertura para uma alteridade radical, um apelo ao "povo que falta".

Palavras-chave: perspectivismo ameríndio, escrita, alteridade.

\section{The people that are missing, we already had them: about writing and perspectivism}

\section{Adriana Bolite Frant}

Based on the Lévi-Strauss's classic "Writing lesson", and guided by Derrida and Librandi-Rocha's re-readings of this text, this article seeks to think how Amerindian perspectivism relates to the broad notion of writing, proposed by Derrida and, also, to the act of creation as suggested by Deleuze. The discussion 
goes on to think about how Amerindian literary theory relates to the Oswaldian maxim "I am only interested in what is not mine", this is to say, it understands literature and writing as an opening to a radical otherness, a plea for the "people who are missing".

Keywords: amerindian perspectivism, writing, otherness.

\section{El pueblo que falta, nosotros ya teníamos: sobre la escritura y perspectivismo}

\section{Adriana Bolite Frant}

A partir del clásico "Lección de escritura", de Lévi-Strauss, y a partir de las relecturas de ese texto efectuadas por Derrida y Librandi-Rocha, este artículo busca pensar cómo el perspectivismo amerindio se relaciona con la noción ampliada de escritura, propuesta por Derrida y aún, con el acto de creación sugerido por Deleuze. La discusión prosigue pensando cómo la teoría literaria amerindia se relaciona con la máxima oswaldiana de que "sólo me intereso por aquello que no es mío", o sea, comprende la literatura y la escritura como una apertura a una alteridad radical, un llamamiento al "pueblo que falta".

Palabras clave: perspectivismo amerindio, escritura, alteridad. 